\title{
DAMAGE TO WATER SUPPLY PIPELINES
}

\author{
MASARU KITAURA ${ }^{\text {i) }}$ and MASAKatsu MiyaJima ${ }^{\text {ii) }}$
}

\begin{abstract}
Earthquake damage to water supply pipelines during the 1995 Hyogoken-Nambu earthquake was investigated. An overview of the damage to water supply pipelines in the Hanshin area is presented and the relationship between the damage to water supply pipelines in Kobe city, geological features and damage to buildings is discussed. The damage is compared with that which occurred from past earthquakes. The study lead to the following conclusions. (1) The majority of failures occurred in pipelines of relatively small diameter. (2) The damage rates for asbestos cement pipe and vinyl pipe were high. The replacement of old pipe such as asbestos cement pipe is urgently required. (3) Joint separations were extensive. Joint separations for cast iron pipe occurred in the older lead and mechanical joints. (4) Liquefaction caused extensive damage to pipelines. The ductile cast iron pipelines with earthquake-proof joint did not suffer damage even in the liquefied area. The effect of earthquake proof joint was confirmed. (5) Since damage to the pipe fittings such as valves, hydrants, etc., was extensive, the strength of the pipe fittings should be improved.
\end{abstract}

Key words: case history, earthquake, earthquake damage, liquefaction, (pipeline), site investigation, underground structure, (IGC: H8/E8)

\section{INTRODUCTION}

An earthquake with magnitude of 7.2 on the Richter scale occurred around Kobe city, Hanshin area at 5:46 on January 17, 1995. 5,502 persons were killed, over 100,000 houses were destroyed and many civil engineering structures were extensively damaged by the earthquake. The water supply system of Kobe city was completely disrupted and its principal functions lost. The water supply systems of the cities in the Hanshin area also suffered severe damage.

The present paper is concerned with the damage to the water supply system during the 1995 Hyogoken-Nambu earthquake. An outline of the water supply system and the damage to it in Kobe, Ashiya and Nishinomiya cities and the system of the Hanshin Water Supply Authority is presented. The damage in Kobe city was also focused on and the relationship between the damage to water supply pipelines, geological features and damage to buildings was investigated. In addition, the damage was compared with that due to earthquakes in the past.

\section{OUTLINE OF WATER SUPPLY FACILITIES AND DAMAGE TO WATER SUPPLY PIPELINE IN HANSHIN AREA}

\section{Hanshin Water Supply Authority}

The Hanshin Water Supply Authority supplies water for Amagasaki, Nishinomiya, Ashiya and Kobe cities. The water supply system of the Hanshin Water Supply Authority has approximately $163 \mathrm{~km}$ of service main and distribution pipelines and serves about 2.5 million customers. The percentage of pipe length to pipe type is shown in Fig. 1. About 38\% of the total length is made up of cast iron pipe (CIP), $23 \%$ ductile cast iron pipe (DCIP), 18\% concrete Hume pipe (HP), 15\% steel pipe (SP) and $6 \%$ asbestos cement pipe (ACP).

The total number of failures for service and distribution pipelines was 120 . The damage rate, defined as the amount of failure per length of pipeline, was about 0.74 / $\mathrm{km}$. Many of the failures occurred at locations along rivers. The damage seems to have been caused in soft ground because many of the areas along the rivers are underlain by soft subsoil. The number of occurrences of damage and the damage rate related to pipe type are illustrated in Figs. 2 and 3. Figs. 4 and 5 show the number of cases of damage and the damage rate related to pipe diameter. These figures indjcate that the majority of the failures occurred in cast iron pipelines of relatively small

i) Professor, Department of Civil Engineering, Kanazawa University, Kodatsuno, Kanazawa, 920.

ii) Associate Professor, Graduate School of Natural Science and Engineering, Kanazawa University, ditto.

Manuscript was received for review on July 28, 1995.

Written discussions on this paper should be submitted before August 1, 1996 to the Japanese Geotechnical Society, Sugayama Bldg. 4F, Kanda Awaji-cho 2-23, Chiyoda-ku, Tokyo 101, Japan. Upon request the closing date may be extended one month. 


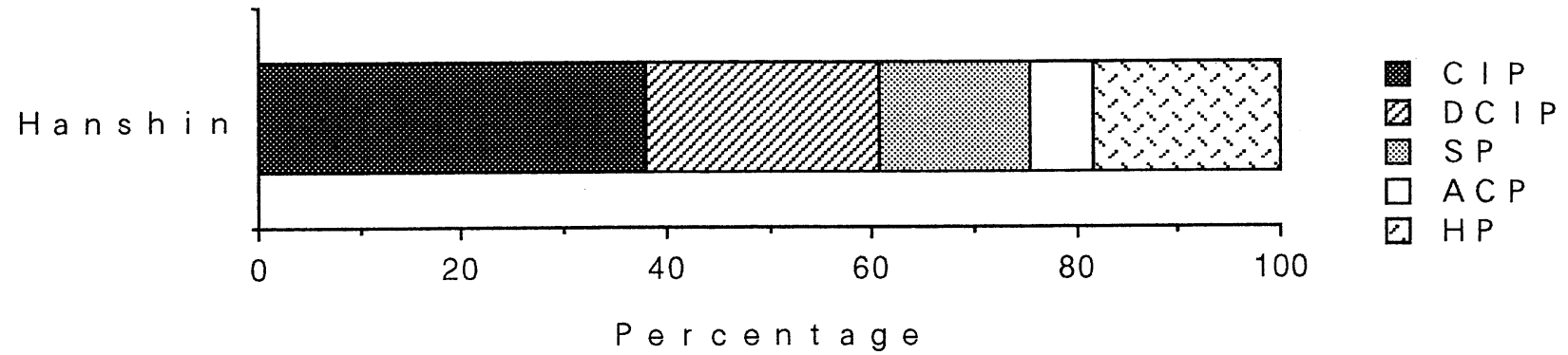

Fig. 1. Percentage of pipe length to pipe type (Hanshin Water Supply Authority)

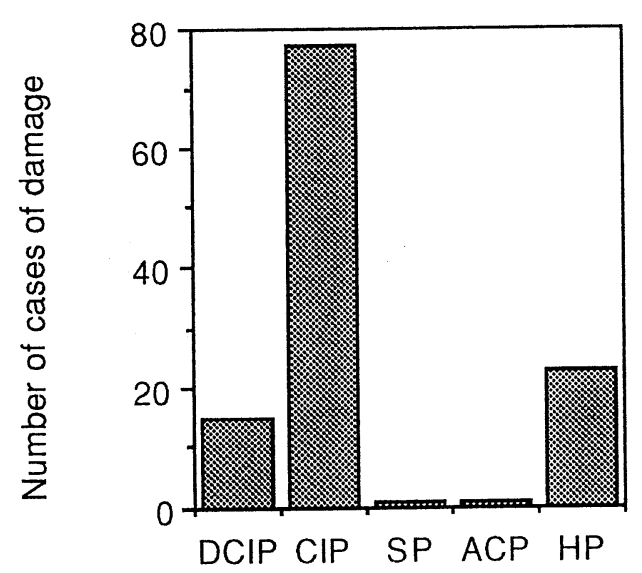

Pipe type

Fig. 2. Number of damage occurrences related to pipe type (Hanshin Water Supply Authority)

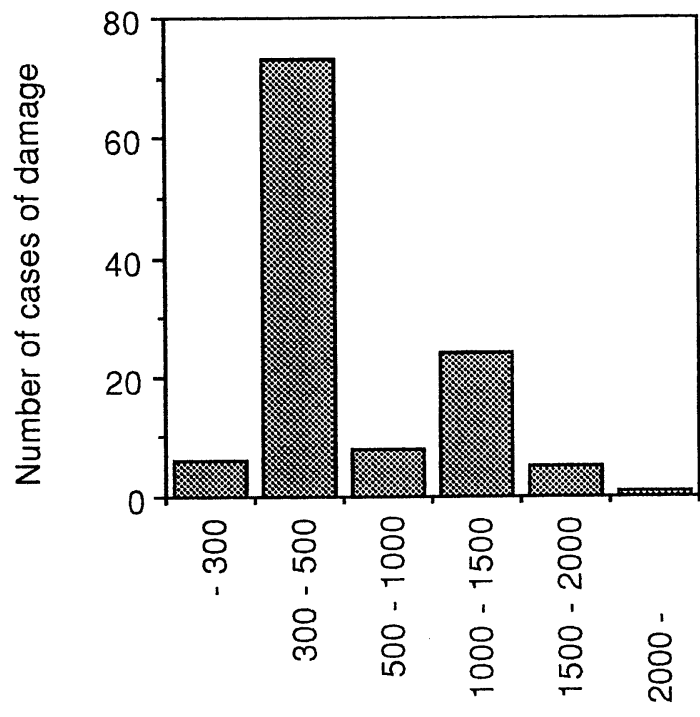

Pipe diameter (mm)

Fig. 4. Number of damage occurrences related to pipe diameter (Hanshin Water Supply Authority)

diameter. The vast majority of the failures occurred at joint separations, and most of them were in older lead and mechanical joints of cast iron pipe.

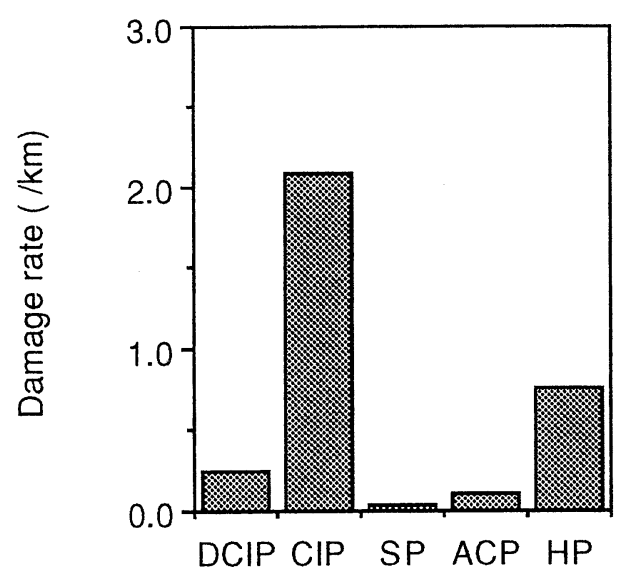

Pipe type

Fig. 3. Damage rate related to pipe type (Hanshin Water Supply Authority)

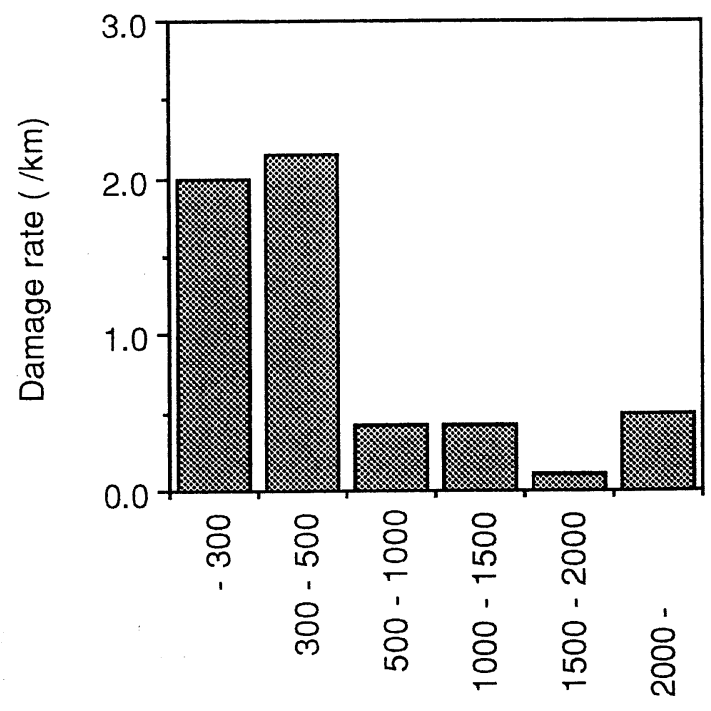

Pipe diameter $(\mathrm{mm})$

Fig. 5. Damage rate related to pipe diameter (Hanshin Water Supply Authority)

\section{Kobe city}

The water supply system of the Kobe Municipal Waterworks Bureau has approximately $4,000 \mathrm{~km}$ of distribu- 


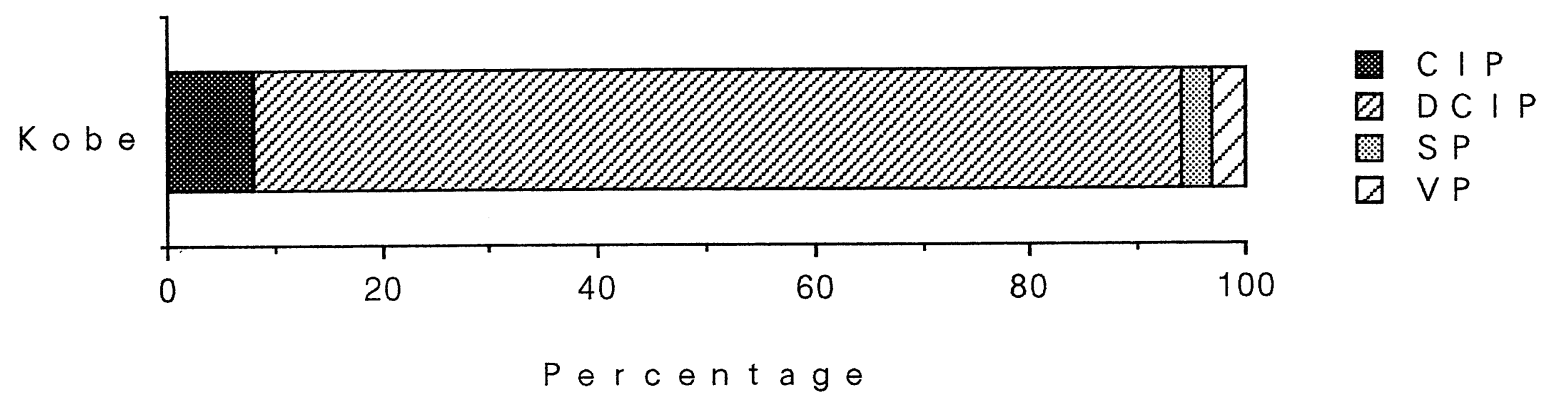

Fig. 6. Percentage of pipe length to pipe type in Kobe city

tion pipelines and serves about 1.5 million customers. Since there is no big river in Kobe city, about $75 \%$ of the amount of water that is supplied from the Kobe Municipal Waterworks Bureau is obtained from the Hanshin Water Supply Authority. The percentage of pipe length to pipe type is shown in Fig. 6 . About $86 \%$ of the total length is made up of ductile cast iron pipe, $8 \%$ cast iron pipe, $3 \%$ vinyl pipe, $3 \%$ steel pipe. It is remarkable that about $86 \%$ of the total length is made up of ductile cast iron pipe (DCIP). The ductile cast iron pipelines with earthquake-proof joint were used for the main pipeline with a diameter of more than $400 \mathrm{~mm}$ and for pipeline buried in soft subsoil such as reclaimed land, high embankment, etc. Fig. 7 shows the cross section of mechanical (K type) and earthquake-proof (S type) joints. The expansion-contraction value of the earthquake-proof joint is $1 \%$ of the length of the pipe. Its length is about $6 \%$ of the total pipe length.

The total number of failures for distribution pipelines was 1,610 as of April 30, 1995. The damage rate was about $0.41 / \mathrm{km}$. Figure 8 indicates the percentage of damage occurrences related to the type of failure. About $64 \%$ of the total failures occurred at a joint and the separation of the pipes at joint was extensive. Figure 9 shows the relationship for damage rate, pipe diameter and type of failure. The damage to pipe fittings such as valves, hydrants, etc. occurred mostly in the large diameter pipelines. It is conceivable that the strength of pipe fittings would not be sufficient to withstand an earthquake. Ductile cast iron pipelines with earthquake-proof joints, however, did not suffer damage even in liquefied areas.

The number of service connection repairs reached to 12,827 in public space and 58,408 within private property

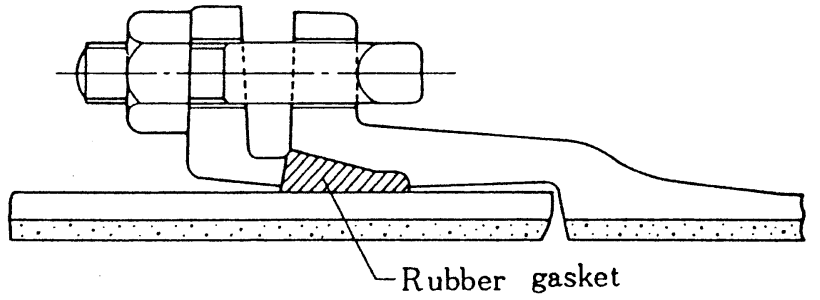

(a) Mechanical joint (K type)

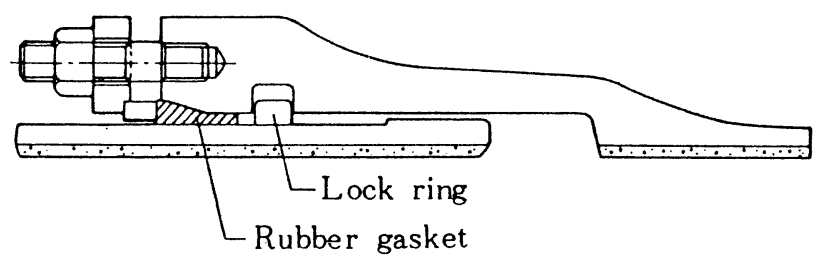

(b) Earthquake-proof joint (S type)

Fig. 7. Cross section of mechanical joint (K type) and earthquakeproof joint ( $\mathrm{S}$ type) for ductile cast iron pipe

as of April 30, 1995. The total number of service connections, therefore, was 71,235. Most of them were caused by pipe breaks and joint separations due to building collapses and road deformation (Matsushita, 1995).

\section{Ashiya city}

The water supply system of the Ashiya City Water Department has approximately $183 \mathrm{~km}$ of distribution pipelines serving about 87,000 customers. The percentage of pipe length to pipe type is illustrated in Fig. 10. About

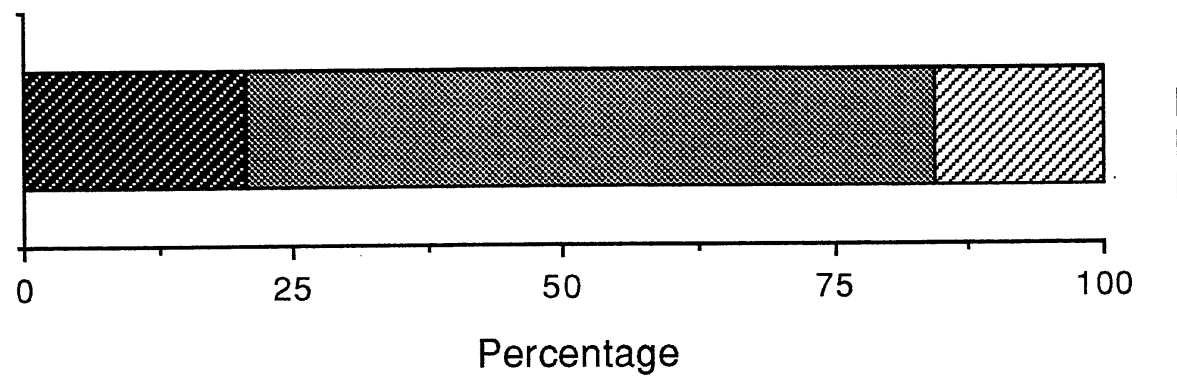

Fig. 8. Percentage of damage occurrences to type of failure in Kobe city

Pipe body

Joint

$\square$ Valve, hydrant, etc. 


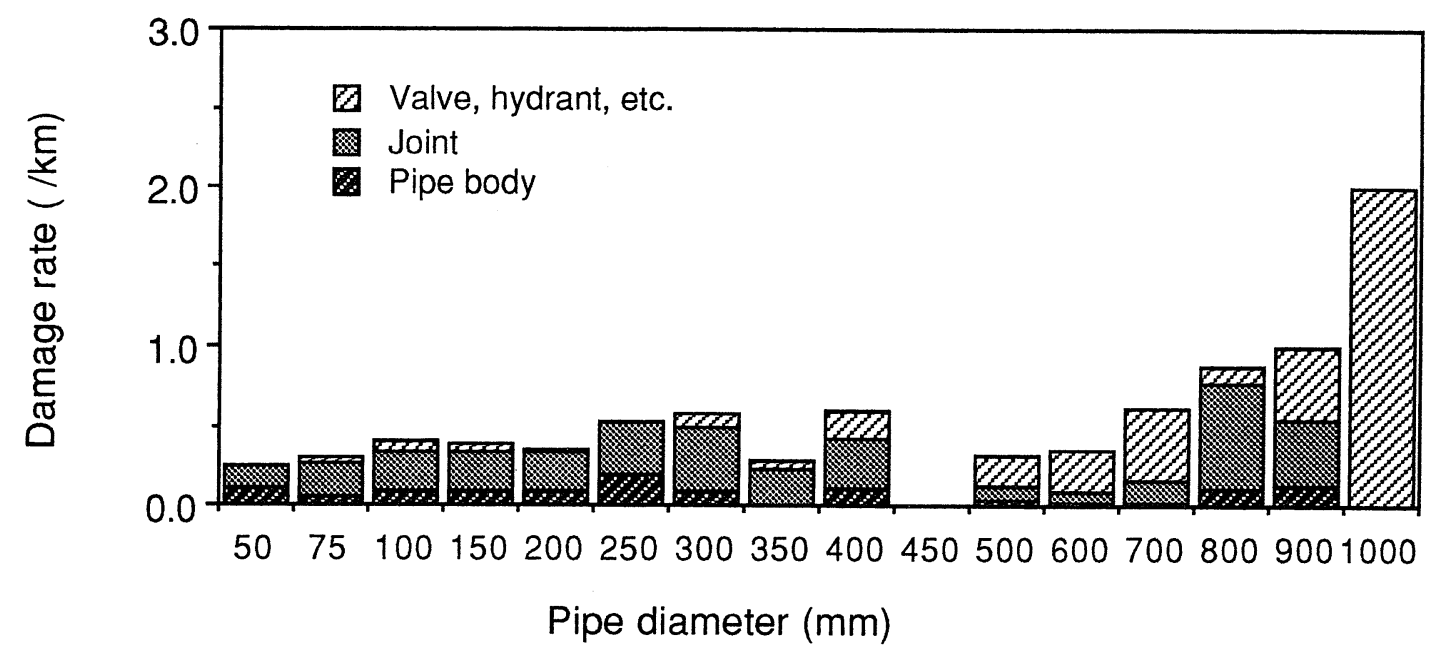

Fig. 9. Relationship for damage rate, pipe diameter and type of failure in Kobe city

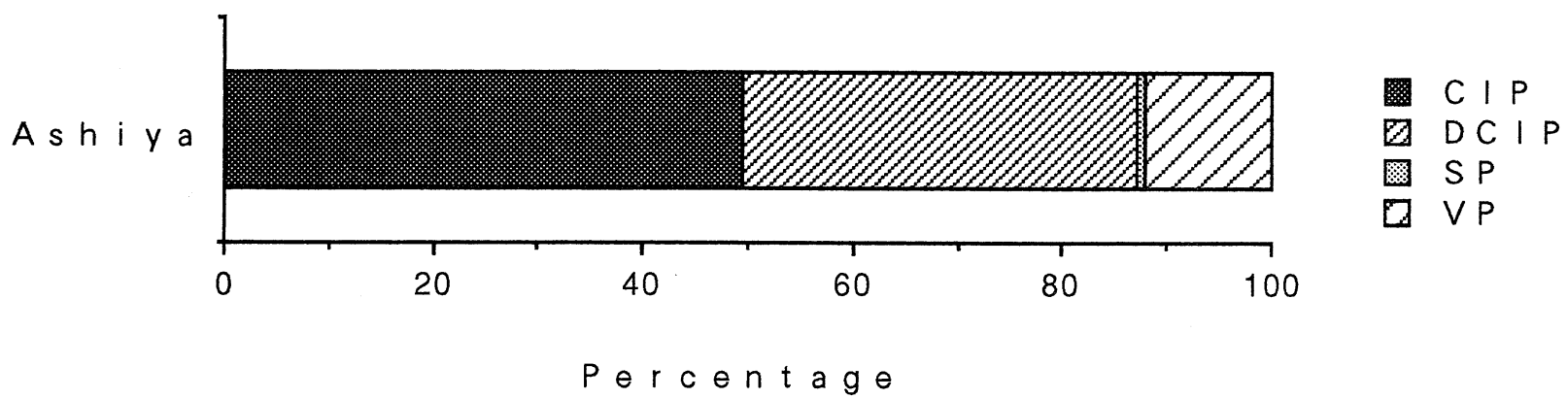

Fig. 10. Percentage of pipe length to pipe type in Ashiya city

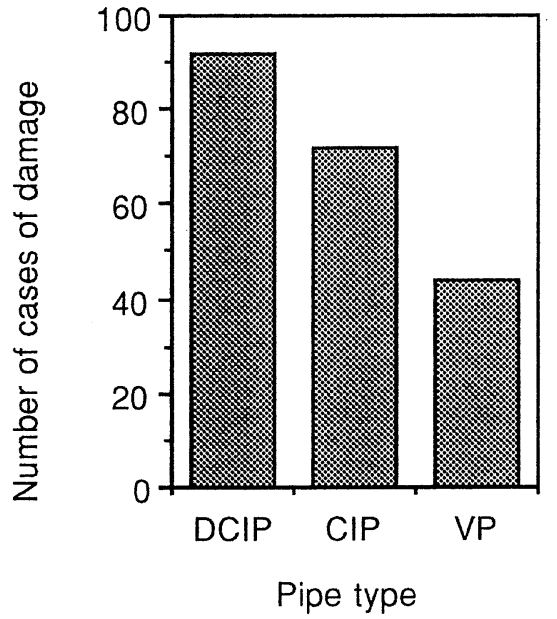

Fig. 11. Number of damage occurrences related to pipe type for Ashiya city

$49 \%$ of the total length is made up of cast iron pipe, $38 \%$ ductile cast iron pipe, $12 \%$ vinyl pipe, $1 \%$ steel pipe.

The total number of failures for distribution pipelines was 340 as of February 28, 1995. The damage rate was about $1.83 / \mathrm{km}$. One hundred and twelve of the total failures were due to damage at valve locations. Figures 11 and 12 show the number of cases of damage and the damage rate related to pipe type. The damage rate for

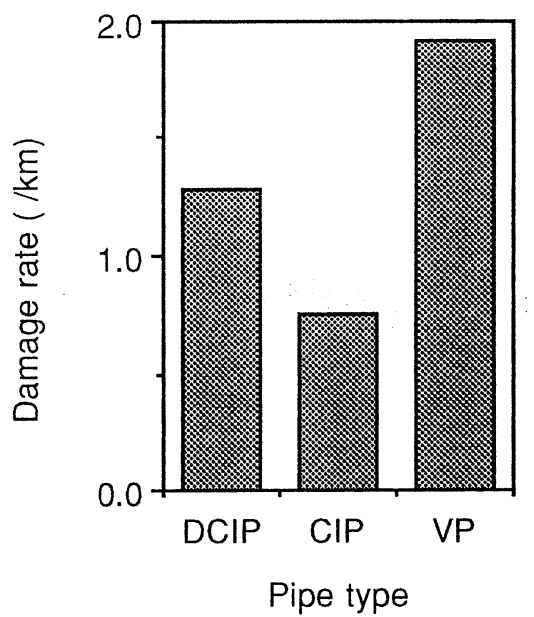

Fig. 12. Damage rate related to pipe type for Ashiya city

vinyl pipe (VP) was the greatest and that for DCIP even greater. Although earthquake-proof joints were not damaged, mechanical joints were damaged at Ashiyahama, where reclaimed land is located. Figures 13 and 14 show the number of cases of damage and the rate of damage in relationship to pipe diameter. The majority of the failures occurred in pipelines with a relatively small diameter. 


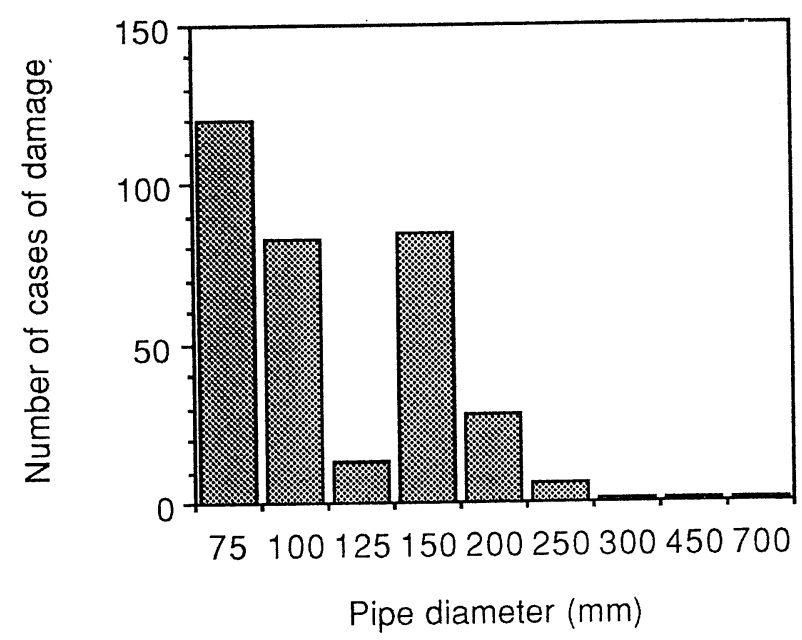

Fig. 13. Number of damage occurrences related to pipe diameter for Ashiya city

\section{Nishinomiya city}

The water supply system of the Nishinomiya City Water Department has approximately $784 \mathrm{~km}$ of distribution pipelines and serves about 422,000 customers. The percentage of pipe length to pipe type is shown in Fig. 15. It is noted that for ACP about $2 \%$ of the total length remains.

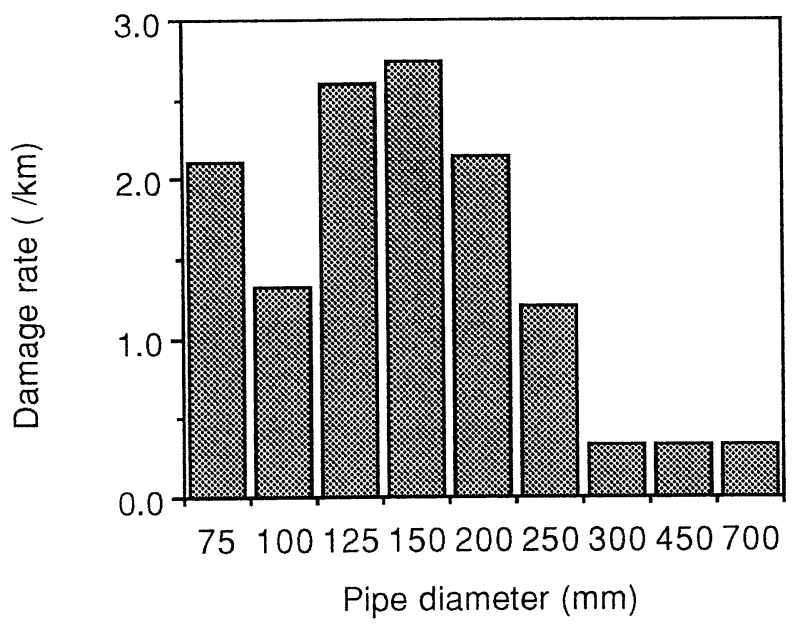

Fig. 14. Damage rate related to pipe diameter for Ashiya city

Since the whole damage was not confirmed, the total damage which occurred up to the end of February, 1995 was used here. The total number of failures for distribution pipelines was 530 and the damage rate was about $0.68 / \mathrm{km}$. The number of cases of damage and the damage rate related to pipe type are illustrated in Figs. 16 and 17. The damage rate for ACP was quite high. Since $\mathrm{ACP}$ is old pipe and its strength is low, replacement of

$\mathrm{Nish}$ i nom i ya
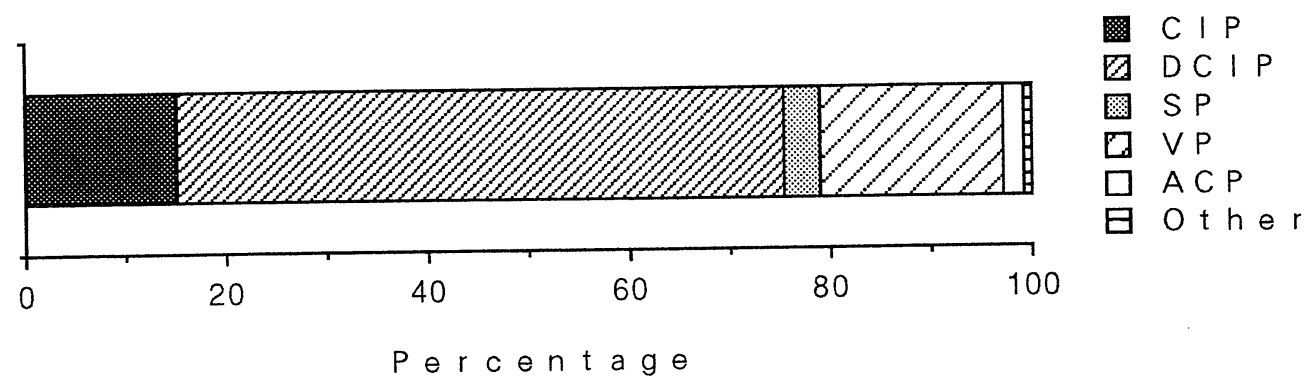

Fig. 15. Percentage of pipe length to pipe type for Nishinomiya city

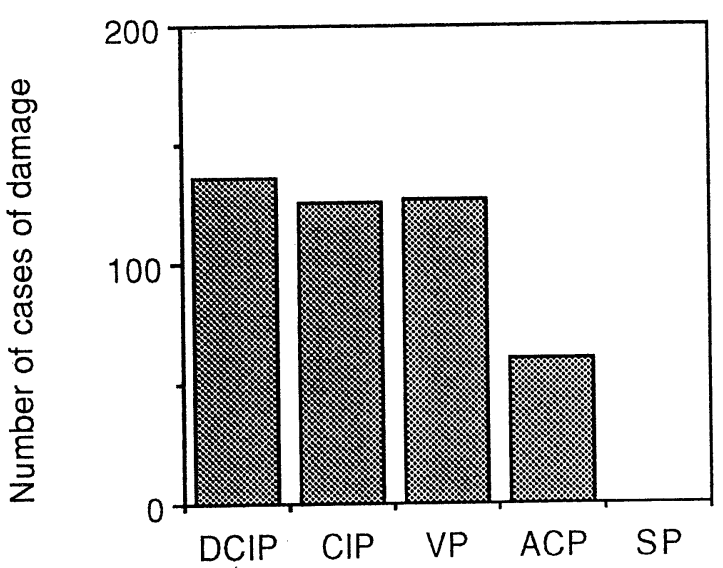

Pipe type

Fig. 16. Number of damage occurrences related to pipe type for Nishinomiya city

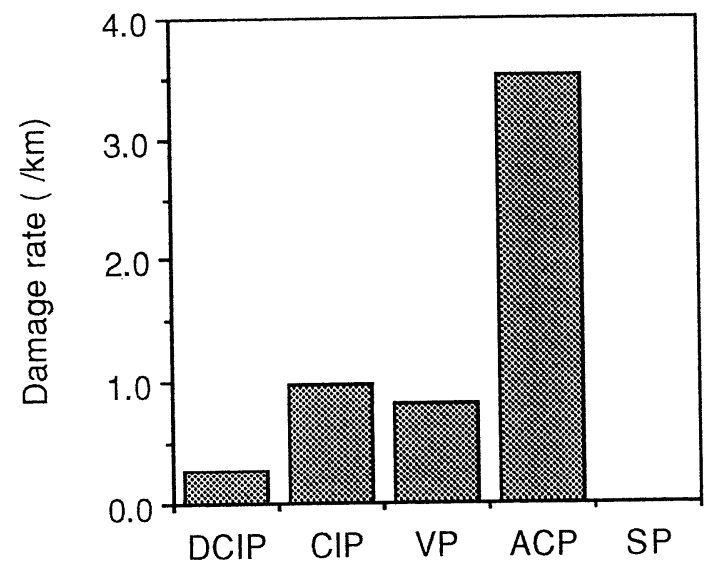

Pipe type 
this pipe is urgently required. Figures 18 and 19 show the number of cases of damage and the rate of damage related to pipe diameter. The majority of failures occurred in pipelines with small diameter.

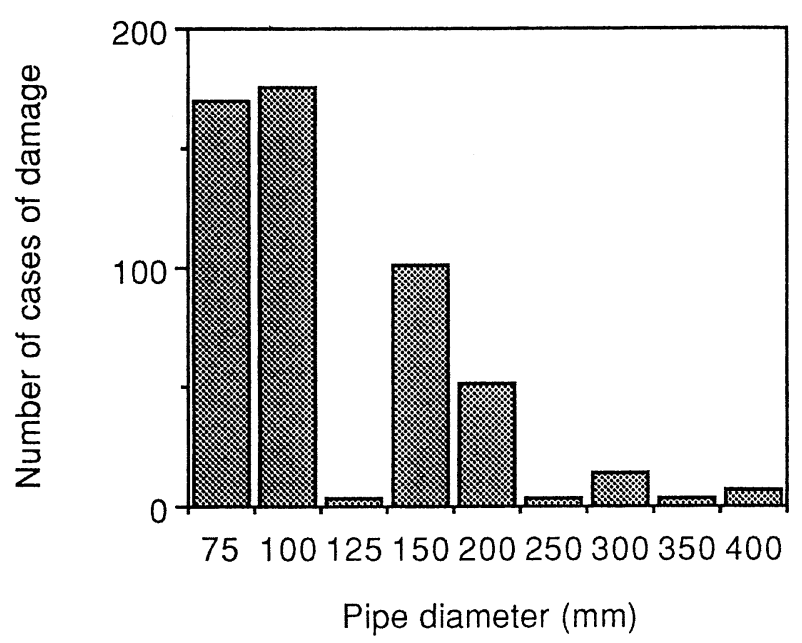

Fig. 18. Number of damage occurrences related to pipe diameter for Nishinomiya city

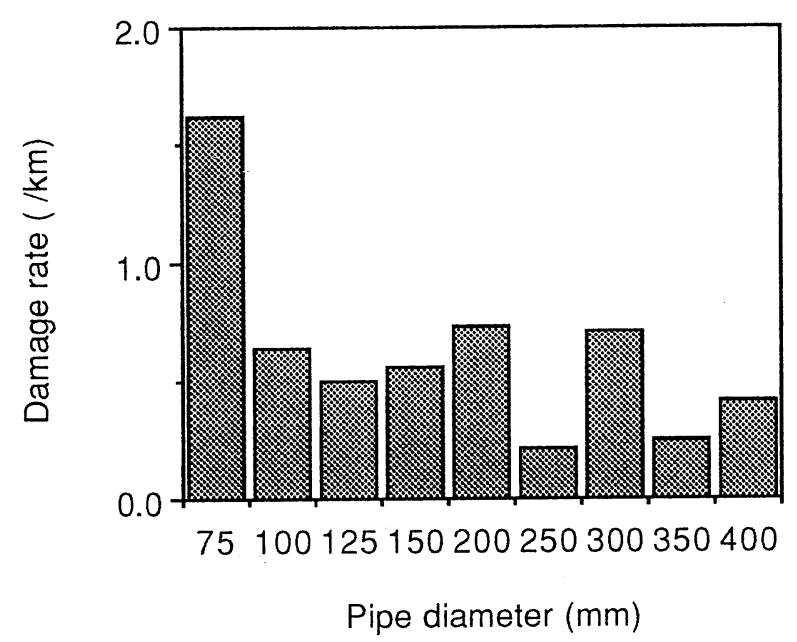

Fig. 19. Damage rate related to pipe diameter for Nishinomiya city

\section{RELATION BETWEEN DAMAGE TO PIPELINES AND GEOLOGICAL FEATURES IN KOBE CITY}

The urban area of Kobe city is situated on a narrow and long strip of land in the east-west direction and its height above sea level varies from $0 \mathrm{~m}$ to $300 \mathrm{~m}$. The topography and geological features, therefore, change drastically there. There are some artificial islands and the reclaimed land is extensive in the southern area of the city. The northern part is mountainous with granite bed rock.

Figure 20 shows the number of cases of damage related the geological features. The number of cases of damage in reclaimed land was the highest and that within alluvium even greater. Pipe failures within soft ground were extensive and liquefaction in reclaimed land affected damage to pipelines strongly. Even the number of cases of damage in basement rock was not as small as expected. The relationship of ground deformation induced by the seismic faults to pipe failure should be investigated in the future. Since the length of piping in each area was not clearly defined unfortunately, the damage rate can not be discussed here.

\section{RELATION BETWEEN DAMAGE TO PIPELINES AND THAT OF BUILDINGS IN KOBE CITY}

Figure 21 illustrates the distribution of damage level for houses and buildings. In this figure, level 5 is defined as that where more than $50 \%$ of wooden houses collapsed and reinforced concrete buildings also collapsed. Level 4 is defined where the rate of collapse of wooden houses was more than $30 \%$ and less than $50 \%$. Level 3 is that for a collapse rate less than $30 \%$. Level 2 is where wall cracking occurs in houses. Level 1 is where slight damage occurs (Chuo Kaihatsu Corporation, 1995). Since a seismic fault was located in the mountain area shown in the upper part of this figure and extending in the east-west direction, the level 5 and 4 areas were also extended in the same direction. The damage level of the area close to the fault was, however, 1 or 2 because of hard subsoil conditions.

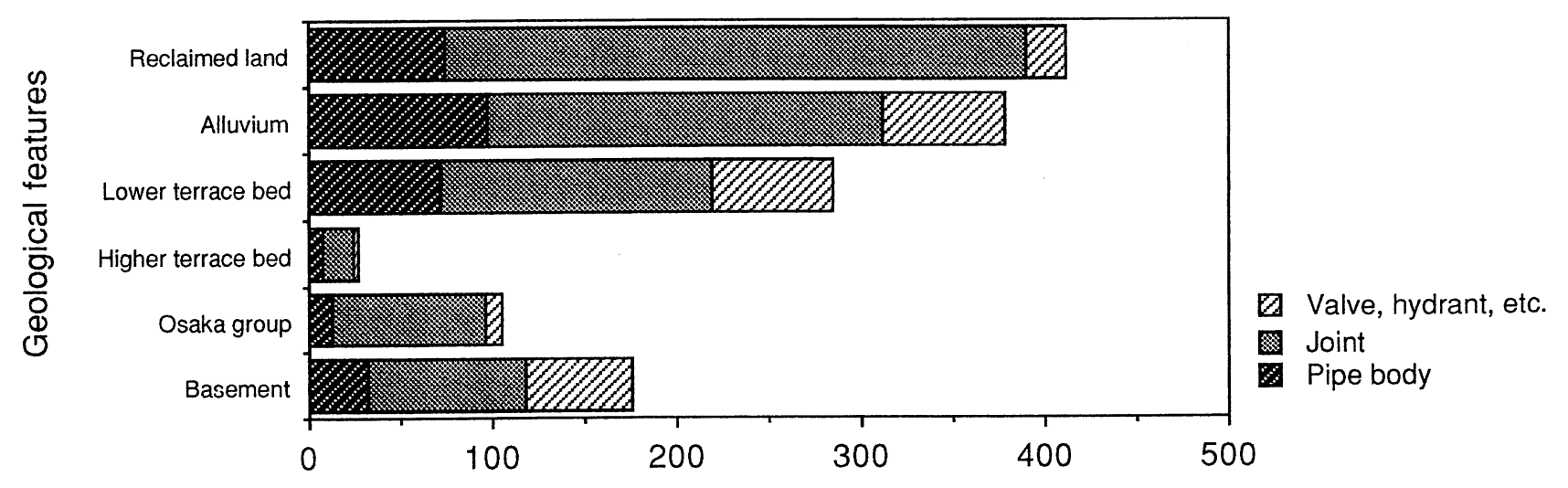

Number of cases of damage

Fig. 20. Relationship between number of damage occurrences and geological features for Kobe city 


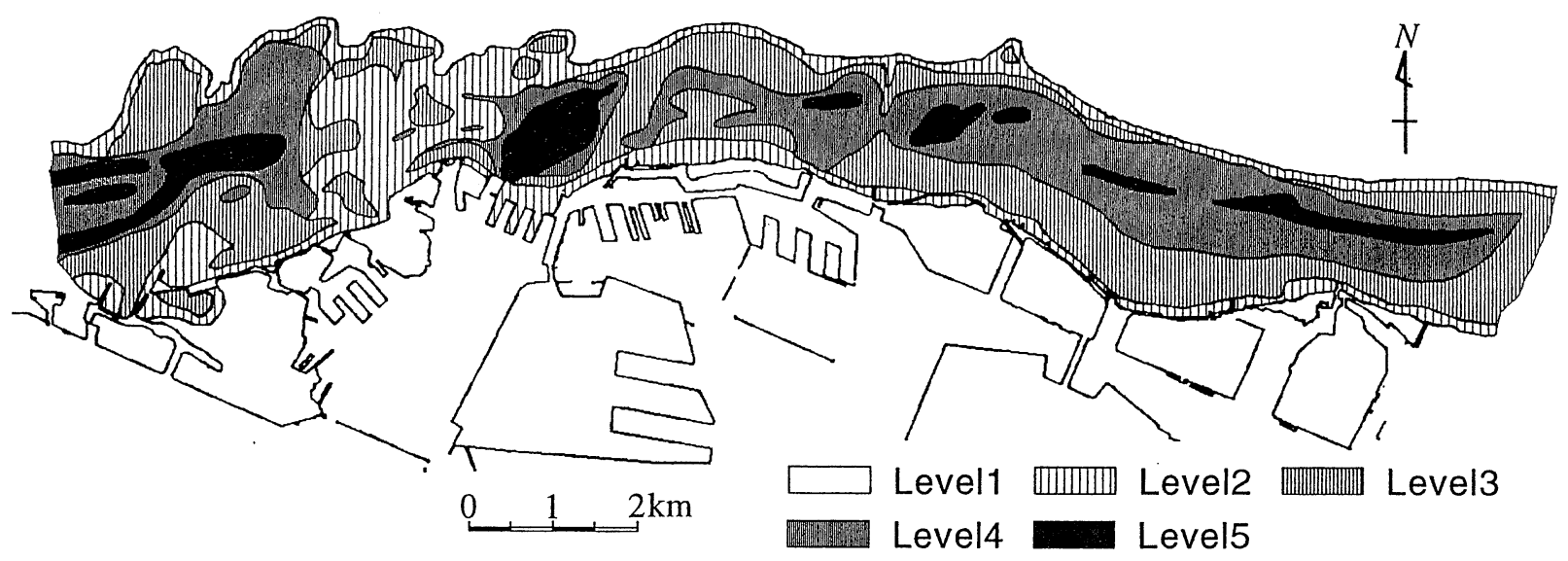

Fig. 21. Distribution of damage level for buildings in Kobe city (after Chuo Kaihatsu Corporation, 1995)

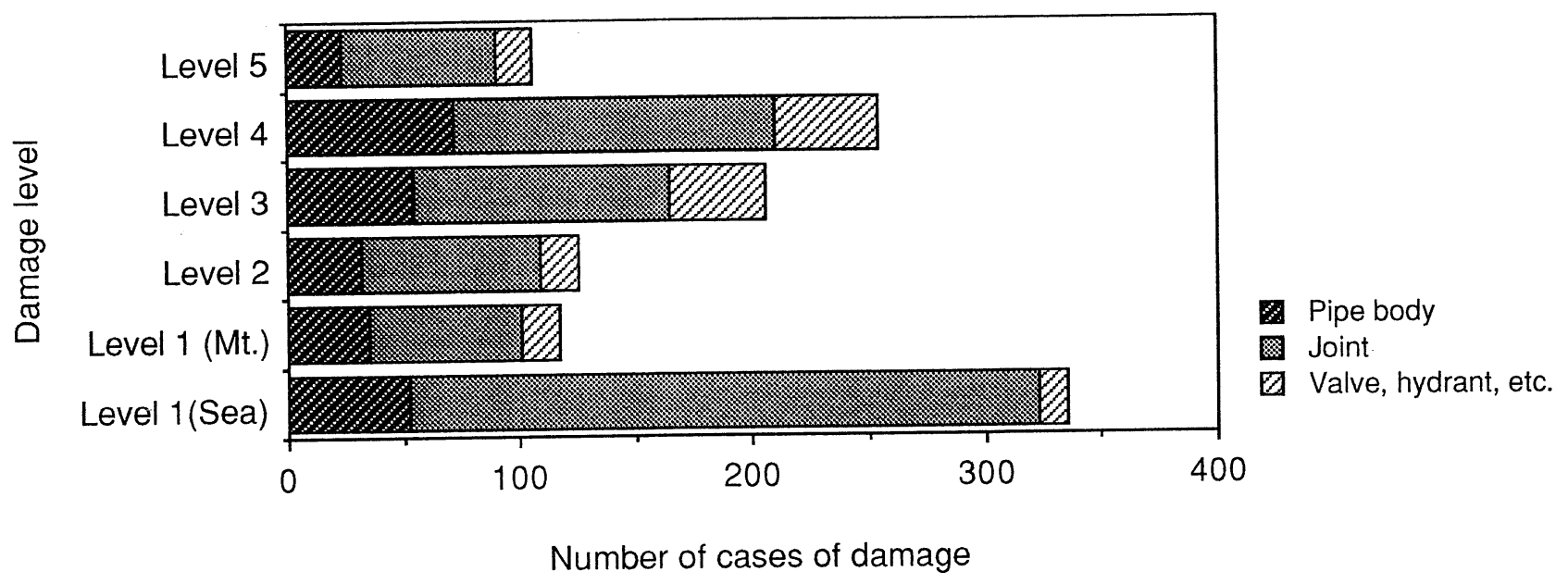

Fig. 22. Number of damage occurrences and damage level for buildings in Kobe city

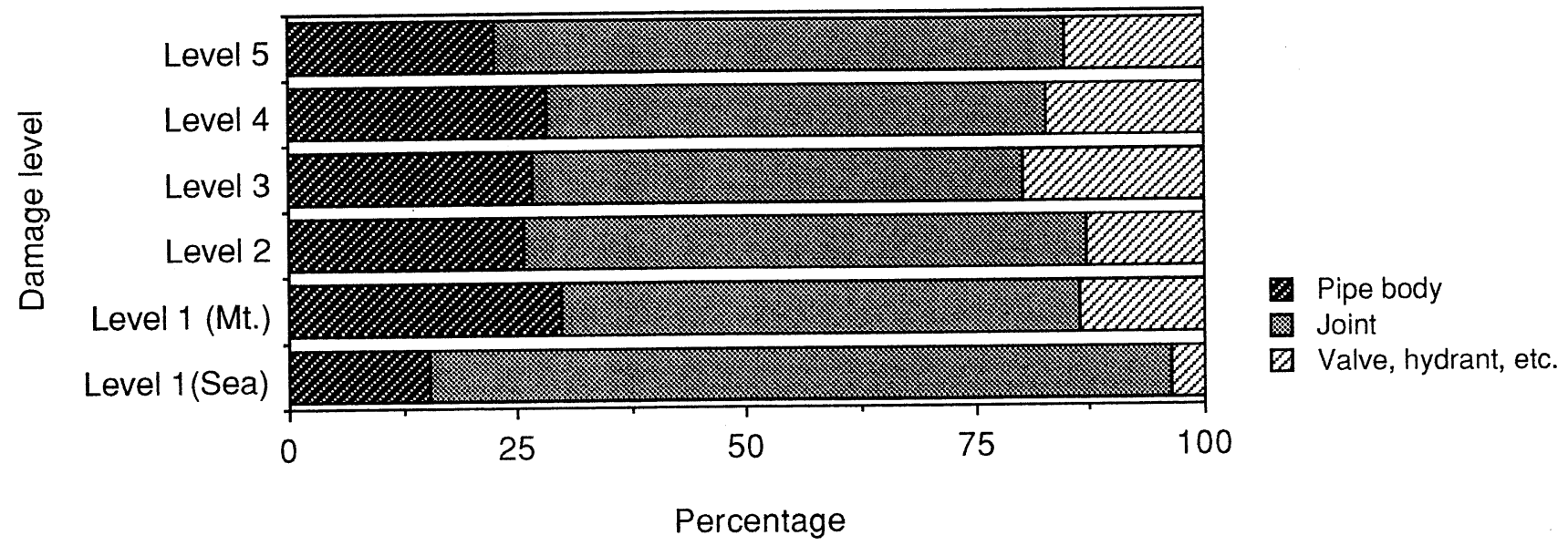

Fig. 23. Percentage of failure type related to damage level for Kobe city

Figure 22 shows the number of cases of damage for each type of failure related to the damage level in houses and buildings and Fig. 23 indicates the percentage of the type of failure at each damage level. Level 1 is classified into two areas: seaside and mountain in this figure. Extensive damage occurred even in the level 1 area, especially, the greatest in the seaside area. The failure of joints was extensive in the seaside area. In the seaside area, 
reclaimed land and alluvium exist. The damage was caused by liquefaction and related ground displacement because liquefaction occurred extensively in the area. The ductile cast iron pipelines with earthquake-proof joint did not suffer damage from soil liquefaction at the seaside. Since the piping length in each area was not clearly defined, the damage rate can not be discussed here.

\section{COMPARISON WITH DAMAGE DUE TO THE PAST EARTHQUAKES}

The damage rate for pipelines related to ground acceleration is shown in Fig. 24. In this figure, the damage rates of pipeline are also plotted for the cities in the epicentral region during the 1989 Loma Prieta earthquake in USA, Niigata city during the 1964 Niigata earthquake, Noshiro city during the 1983 Nihonkai-chubu earthquake and Hachinohe city during the 1994 Sanriku Haruka-oki earthquake in Japan (Miyajima, 1991; Miyajima et al., 95). Since liquefaction was extensive in the Marina district in San Francisco during the 1989 Loma Prieta earthquake, the damage rate was evaluated only in this district. The 1964 Niigata and the 1983 Nihonkai-chubu earthquakes caused severe liquefaction-induced damage to buried pipelines over a large area (Kitaura et al., 1988).

This figure suggests that the damage rate increases with an increase in ground acceleration. The damage rates in the Marina district, Niigata and Noshiro cities were extensive because of extensive liquefaction. The damage rates for cities in the Hanshin area were smaller than those of Niigata and Noshiro cities because the liquefaction area was limited. Although liquefaction also took place in the cities of Santa Cruz and Watsonville, the damage rate

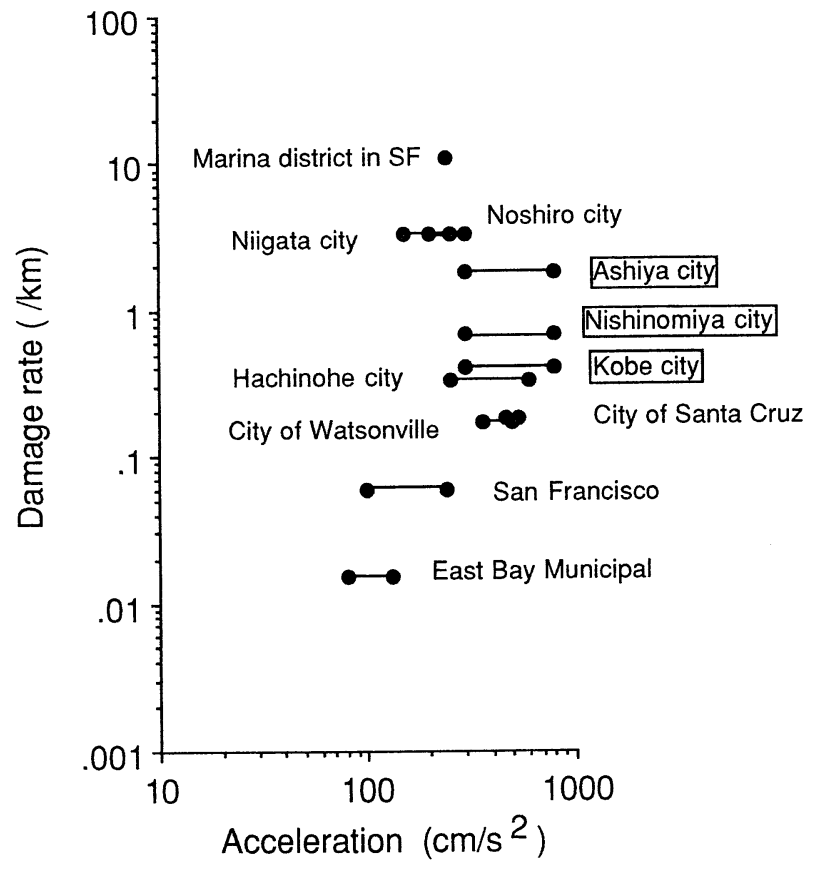

Fig. 24. Relationship between damage rate and peak ground acceleration was also not high (Miyajima, 1991). This is because the damage rate is defined as a number of cases of damage per length of piping. As liquefaction is affected by local soil conditions, if the damage rate is calculated only for the liquefied area, it is remarkably high. If the damage rate is evaluated for an entire city with a large total area but a limited liquefied area, however, it is relatively low. The damage rates for the Marina district and San Francisco are shown in Fig. 24 as an example. Although the damage rate for the Marina district was great because the rate is evaluated only for the liquefied area, the rate of the entire city of San Francisco was considerably lower. The damage rate is also affected by the size of a piping area and the effect is especially great when local ground failure such as liquefaction occurs. The damage rate of pipelines must therefore be discussed from this perspective.

\section{CONCLUSIONS}

An outline of the damage to water supply pipelines from the 1995 Hyogoken-Nambu earthquake was presented and the relationship of the damage to ground conditions was discussed. The following conclusions may be drawn based on the present study.

(1) The majority of failures occurred in the pipelines of relatively small diameter.

(2) The damage rates for asbestos cement pipe and vinyl pipe were extensive. The replacement of old pipe such as asbestos cement pipe is urgently required.

(3) Joint separations were extensive. For cast iron pipe, joint separations usually occurred in the older lead and mechanical joints.

(4) Liquefaction causes heavy damage to pipelines. The ductile cast iron pipelines with earthquake-proof joint, however, did not suffer damage even in the area where liquefaction occurred. The reliability of the earthquake proof joint was confirmed.

(5) Since damage to pipe fittings such as valves, hydrants, etc., was also extensive, the strength of the pipe fittings should be improved.

\section{ACKNOWLEDGMENTS}

The present paper is based on data collected from a detailed investigation. Many individuals and organizations generously helped with this investigation. In particular, we are deeply indebted to Prof. S. Takada of Kobe University and the staff of the Kobe Municipal Waterworks Bureau for their help. This study was supported in part by the Grant-in-Aid for Scientific Research from the Ministry of Education, Science and Culture of Japan (No.07650539).

\section{REFERENCES}

1) Chuo Kaihatsu Corporation (1995): “Quick investigation report on the Great Hanshin Earthquake Disaster." 
2) Kitaura, M. and Miyajima, M. (1988): "Quantitative evaluation of damage to buried pipelines induced by soil liquefaction," Proceedings of the 9th World Conference on Earthquake Engineering, Vol. 7, pp. 11-16.

3) Matsushita, M.(1995): "Damage of Kobe water system by the Hanshin Awaji Great earthquake and restoration plan," Proceedings of 6th US-Japan Workshop on Earthquake Disaster Prevention for Lifeline Systems, Osaka, Japan.
4) Miyajima, M. (1991): “Performance of water supply pipelines due to the Loma Prieta earthquake of October 17, 1989," Journal of Japan Society for Natural Disaster Science, Vol. 10, No. 1, pp. 145157.

5) Miyajima, M. and Kitaura, M. (1995): "Earthquake performance of water supply pipelines during the recent earthquake in Japan," Proceedings of Pacific Conference on Earthquake Engineering '95, Vol. 2, pp. 911-916. 